\title{
PENERAPAN KUALITAS PELAYANAN DALAM MENINGKATKAN KEPUASAN KONSUMEN PADA PT ETOS SURYANUSA
}

\author{
Karolus Putra Setiadi, Leonard Adrie Manafe * \\ Sekolah Tinggi Ilmu Ekonomi Mahardhika Surabaya \\ *Email : leonard.adrie@stiemahardhika.ac.id
}

\begin{abstract}
Business sustainability and company goals can be measured by the company's level of service to customer satisfaction. With the recognition of customer satisfaction, it means that the use of products or services can continue and of course the company will get definite and smooth profits and business. The purpose of this study is to determine customer satisfaction is determined by the level of service of the company. Descriptive qualitative research method provides an overview of the results of the analysis that is easily accessible to readers. The research sample consisted of 30 informants who had become consumers of PT Etos Suryanusa. Research data collection was carried out through distributing questionnaires, taking documentation and direct interviews. The results obtained from the research are physical evidence factors, reliability factors and responsiveness factors are important factors in increasing consumer satisfaction. The reliability factor has the most dominant influence on customer satisfaction. Assurance and empathy factors do not have any effect on customer satisfaction, instead they are considered as inhibiting factors for service quality
\end{abstract}

Keywords: Quality of Service, Customers Satisfaction, Consumers of PT Etos Suryanusa

ABSTRAK : Keberlanjutan usaha dan pencapaian tujuan perusahaan dapat diukur dengan tingkat pelayanan perusahaan terhadap kepuasan konsumen. Dengan adanya pengakuan akan kepuasan konsumen berarti pemakaian produk atau jasa dapat berlanjut dan tentu saja perusahaan akan memperoleh keuntungan dan keberlanjutan usaha yang pasti dan lancar. Yang menjadi tujuan inti dari penelitian ini adalah untuk mengetahui kepuasan konsumen dipengaruhi oleh tingkat pelayanan perusahaan. Metode penelitan kualitatif deskriptif memberikan gambaran dari hasil analisa yang mudah dipahami oleh pembaca. Sampel penelitian sebanyak 30 informan yang sudah menjadi konsumen PT Etos Suryanusa. Pengumpulan data penelitian dilakukan melalui penyebaran kuesioner, pengambilan dokumentasi dan wawancara informan secara langsung. Hasil yang diperoleh dari penelitian adalah faktor bukti fisik, faktor kehandalan dan faktor daya tangkap merupakan faktor yang penting dalam meningkatkan kepuasan konsumen. Faktor kehandalan memiliki pengaruh paling dominan dalam kepuasan konsumen. Faktor jamian dan faktor empati tidak memiliki pengaruh apapun terkait dengan kepuasan konsumen, malah dianggap sebagai faktor penghambat kualitas pelayanan. 


\section{PENDAHULUAN}

Perusahaan dengan berbagai upaya dalam menghadapi ketat dan tingginya persaingan bisnis dituntut untuk lebih memiliki keunggulan dalam bersaing. Dengan memiliki keunggulan bersaing diharapkan dalam setiap harinya senantiasa memperoleh pangsa pasar yang terus bertumbuh. Strategi pemasaran harus ditentukan atau ditetapkan oleh perusahaan agar dapat bertahan mampu mengatasi persaingan dan tujuan perusahaan dapat tercapai. Tingginya tingkat pertumbuhan penduduk dan perkembangan pembangunan merupakan suatu indikasi bahwa persaingan dalam dunia bisnis juga akan semakin tinggi dan ketat. Peluang dalam melakukan usaha atau bisnis akan semakin terbuka dan menjanjikan. Salah satu peluang dimaksud adalah usaha yang bergerak dalam bidang jasa pengendalian hama atau dikenal dengan istilah asing ialah pest control.

Istilah pest control dalam bahasa asing diterjemahkan pest adalah hama dan control adalah pengendali. Berarti pest control dalam bahasa Indonesia dapat diartikan sebagai pengendalian hama, bukan diterjemahkan sebagai pembasmian hama. Kata pengendalian yang dipilih mengandung makna bahwa pada pokoknya hama yang ada disekitar manusia tidak bisa dimatikan atau dimusnahkan. Hal ini disebabkan karena merupakan kesatuan rangkaian ekosistem lingkungan hidup (Wedastra, 2020).

Terdapat beberapa hama yang sifatnya suka mengganggu seperti nyamuk, kecoa, lalat dan sebagainya. Tetapi terdapat juga hama yang sifatnya ganda suka mengganggu dan sekaligus merusak seperti tikus yang memiliki sifat mengerat dan rayap yang paling membahayakan karena suka merusak bangunan. Apabila suatu bagian dari bangunan ditempati rayap maka untuk memberantasnya akan menjadi lebih sulit. Dengan tingkat kesulitan itulah maka perusahaan khusus yang bergerak dalam bidang pengendalian hama sangat dibutuhkan perannya, istilah popular yaitu pest control services company. Tidak sembarang bagi seseorang yang masuk bekerja dalam bidang ini, wajib dibutuhkan keahlian yang tersertifikasi, terlatih dan mahir dalam pengetahuan akan tingkah laku hama. Cakupan area dibatasi pada pengendalian hama perkotaan (urban pest) saja tidak sampai mencakup pengendalian hama pertanian atau perkebunan. Untuk membedakan pengendalian hama pertanian atau perkebunan terdapat istilah penting 
Revised: July, 232021

Available online : July, 242021

yaitu perlindungan tanaman (crop

protection). Jenis hama yang biasanya

dikendalikan terkait pest control adalah serangga terbang seperti lalat dan nyamuk, serangga merangkak seperti kecoa dan semut, rayap, tikus, hama gudang seperti kutu, ulat, kumbang dan ngengat serta pengendalian hama spesifik seperti kaki seribu, laba-laba, tokek, kelelawar, kaki seribu, kucing, cecak, anjing, musang dan burung. Praktisi usaha pest control umumnya melakukan pengendalian melalui penyemprotan penyemprotan, pengembunan, pengumpanan, pemberian bubuk dan penggasan. Pemakaian bahan pestisida (kimia beracun) digunakan untuk melakukan tindakan pengendalian, karena itu perlu ditangani oleh orang yang mempunyai keahlian dan profesional dalam bidang pengendalian hama. Dengan adanya usaha pest control ini akan menjadikan kehidupan kota lebih nyaman dan higienis, jauh dari serangan hama dan terjangkitnya risiko sakit yang akan berpengaruh terhadap kerugian ekonomi negara. Pest control membuat pikiran masyarakat perkotaan menjadi tenang (peace of mind). Kesadaran masyarakat akan menjadi nyata tatkala upaya untuk mengendalikan hama dapat dilakukan seutuhnya. Pandangan awam dengan adanya kegiatan pest control ini tidak hanya melakukan pemberantasan atau pengusiran hama melainkan pencegahan dengan melakukan semua kebiasaan baik masyarakat dan setiap waktu dapat menunjukan rasa tanggung jawab atas kegiatan yang dilakukan sehariannya. Pemakaian bahan pestisida akan cenderung mengalami penurunan bahkan nantinya tidak lagi digunakan.

Umumnya terdapat tiga kelompok konsumen pest control antara lain konsumen perumahan, konsumen industry seperti pergudangan dan pabrik dan konsumen komersial seperti perkantoran, hotel, restoran, kafe, apartemen, plaza, institusi pendidikan, pusat kebugaran dan lainnya. Dengan melihat kelompok konsumen dan berbagai karakteristik yang melekatnya, perusahaan pest control dituntut untuk memberikan pelayanan yang prima agar kepuasan konsumen dapat terpenuhi.

Kualitas pelayanan dapat diartikan sebagai suatu tindakan yang aktif dilakukan terkait pemenuhan kebutuhan konsumen akan produk/jasa yang melampaui harapan konsumen (Tjiptono, 2007). Untuk mengetahui tingkat kualitas pelayanan dapat dilakukan dengan cara membuat perbandingan terkait persepsi 
yang nyata yang di dapat konsumen dengan tingkat layanan yang benar-benar terjadi sesuai harapan dan keinginan konsumen yang berhubungan dengan atribut layanan perusahaan. Apabila pelayanan dapat dirasakan baik sejalan dengan harapan konsumen maka persepsi konsumen terkait kualitas layanan dapat dikatakan baik dan puas. Apalagi kualitas layanan yang super baik dan berkualitas yang melampaui harapan konsumen. Kebalikannya, apabila konsumen merasa kualitas layanan yang diberikan rendah bahkan buruk maka akan membentuk persepsi konsumen menjadi jelek terkait kualitas pelayanan. Untuk itu baik atau tidaknya mutu suatu layanan dapat diukur dari seberapa besar kemampuan perusahaan pemberi jasa melakukan pelayanan yang cocok dan konsisten sejalan dengan harapan konsumen.

Indikator pelayanan konsumen dapat diukur dan dinilai kualitasnya melalui alat ukur yang dikenal dengan sebutan SERQUAL (Servive Quality). Terdapat lima dimensi SERQUAL terkait pengukuran persepsi konsumen terhadap kualitas layanan antara lain: a) Tangibles (bukti langsung), merupakan kemampuan suatu perusahaan dalam memberikan pelayanan kepada pihak luar dengan pembuktian yang nyata terkait pelayanan yang diberikan. Bukti langsung adalah wujud secara fisik terkait pelayanan mencakup fasilitas yang diberikan, kecanggihan alat teknologi yang digunakan, keahlian sumber daya manusia dan sarana prasarana terkait informasi/komunikasi (Wijaya, 2018). Kesan pertama yang timbul dipikiran konsumen yaitu dengan melihat tampilan fisik. Untuk itu harus menjadi perhatian khusus perusahaan terkait pemberian kesan positif bagi konsumen; b) Reliability (kehandalan), merupakan bentuk kemampuan perusahaan untuk mencukupi kebutuhan konsumen dengan cepat dan memuaskan sesuai dengan janji sebelumnya yang ditawarkan; c) Responsiveness (daya tangkap), merupakan kemampuan perusahaan dalam melakukan pelayanan yang cepat, tanggap dan tepat kepada konsumen dengan kejelasan informasi yang disampaikan; d) Assurance (jaminan), merupakan bentuk keyakinan akan pengetahuan yang dimiliki oleh karyawan perusahaan agar konsumen merasa memiliki ketergantungan penuh akan pelayanan yang diberikan perusahaan. Bentuk jaminan yang diberikan oleh karyawan perusahaan antara lain pemberian informasi atau berita 
Revised: July, 232021

Available online : July, 242021

dengan menggunakan bahasa yang sopan dan tata bahasa yang mudah dimengerti konsumen, sifat kejujuran untuk menumbuhkan kepercayaan konsumen akan kredibilitas perusahaan, tingginya keyakinan konsumen terhadap pelayanan yang diberikan perusahaan, keahlian karyawan perusahaan dalam memberikan pelayanan kepada konsumen serta jaminan kesopanan dan keramahtamahan terkait sikap dan perilaku karyawan perusahaan; e) Empathy (empati), berhubungan dengan keinginan konsumen yang harus dipahami oleh perusahaan.

Kepuasan konsumen adalah suatu perasaan yang dimiliki oleh konsumen setelah melakukan perbandingan kinerja atau hasil yang dinikmati dengan harapannya (Kotler, 2002). Karangan buku lainnya, kepuasan konsumen diartikan sebagai suatu perasaan kecewa atau tidaknnya konsumen yang timbul setelah melakukan perbandingan antara persepsi atau kesan konsumen akan kinerja atau hasil suatu produk dengan semua harapan konsumen (Hakim, 2021)

Faktor kepuasan konsumen telah lama menjadi perhatian oleh beberapa ahli pemasaran, hal dikarenakan apabila kepuasan konsumen muncul maka kecenderungan konsumen untuk menjadi loyal akan pemakaian produk atau jasa perusahaan sehingga bisnis perusahaan akan berkelanjutan. Terdapat beberapa indator terkait dengan variabel kepuasan konsumen (Candrianto, 2021) antara lain: a) Kualitas produk, tingginya mutu suatu produk yang digunakan akan berpengaruh terhadap kepuasan konsumen. Oleh karena itu penyediaan produk yang bermutu harus selalu diberikan perusahaan karena konsumen sudah mengeluarkan banyak beban atau biaya untuk mendapatkan produk tersebut; b) Kualitas pelayanan, konsumen menginginkan agar pelayanan yang diberikan perusahaan sesuai dengan harapannya. Lebih khusus bagi perusahaan yang bergerak dalam bidang jasa, faktor pelayanan menjadi sangat penting dan harus menjadi perhatian serius bagi perusahaan. Pelayanan yang baik akan membentuk persepsi konsumen terhadap kelangsungan usaha. Kepuasan pelanggan memiliki pengaruh besar akan penggunaan produk atau jasa secara berkelanjutan; c) Emosional, secara emosional terdapat beberapa konsumen yang memiliki rasa kepuasan tersendiri dalam memakai produk atau jasa yang dibeli. Hal ini terkait nilai sosial dimana pihak lain akan terpengaruh dan takjub dengan melihat apa yang digunakan konsumen. Kebanggaan 
konsumen karena menggunakan merek produk tertentu; d) Harga, berbicara terkait harga suatu produk, konsumen akan melakukan perbandingan harga antara beberapa merek. Kebanyakan konsumen merasa puas akan produk atau jasa yang dibeli dengah harga yang relatif tidak mahal tapi bermutu; e) Kemudahan, kepuasan konsumen terjadi jika produk atau jasa relatif mudah diperoleh, nyaman dalam menggunakan dan pelayanan yang efisien. Beberapa penelitian terdahulu terkait dengan kualitas layanan yang memiliki pengaruh terhadap kepuasan konsumen.

Penelitian yang dilakukan oleh Kamaludin (2019:47-55) dengan responden yaitu konsumen Apotik Puji Lestari Majalengka. Metode penelitian peninjauan dengan teknik pengumpulan data melalui pembagian kuesioner, survei dan wawancara langsung. Hasil penelitian menunjukan terdapatnya pengaruh yang kuat dari kualitas layanan terhadap kepuasan konsumen.

Penelitian oleh Krisdianti (2019:3644), sample penelitian sebanyak 97 konsumen Restoran Pizza Hut Malang Town Square. Teknik pengambilan sample purposive sampling. Penelitian menghasilkan bahwa kualitas layanan konsumen dengan variabel empati mempunyai pengaruh paling besar terhadap kepuasan konsumen.

Penelitian selanjutnya oleh Setiawan (2019:114-126), jumlah sample penelitian 100 konsumen PT Borwita Citra Prima Bondowoso, jenis penelitian kuantitatif deskriptif. Hasil penelitian diperoleh kualitas pelayanan (daya tangkap, kehandalan, jaminan, bukti fisik dan empati) secara bersama-sama memiliki pengaruh positif dan signifikan terhadap kepuasan konsumen.

Berdasrkan latar belakang, tinjauan literatur dan penelitian terdahulu yang telah dijabarkan diatas, maka penting dilakukan penelitian untuk mengetahui kualitas pelayanan PT Etos Suryanusa yang memiliki pengaruh terhadap kepuasan konsumen.

\section{METODE PENELITIAN}

Metode kualitatif deskriptif digunakan dalam penelitan ini, menganalisis suatu fenomena atau peristiwa serta aktivitas yang sedang terjadi. Hasil yang didapat berupa gambaran hasil analisis sehingga dengan mudah dipahami oleh pembaca (Hamdi, 2014). 
Revised : July, 232021

Available online : July, 242021

\section{Penelitian dilaksanakan di PT. Etos}

Suryanusa Surabaya, sejak bulan awal Maret sampai Mei 2021. Lokasi perusahaan Keboansikep, Gedangan, Sidorjo, Jawa Timur.

\section{Sampling Penelitian}

Informan penelitian sebanyak 30 partisipan yang dibagi dalam tiga golongan konsumen, 21 informan golongan konsumen perumahan, 4 (empat) informan golongan konsumen restoran dan 5 (lima) informan golongan konsumen industri.

\section{Definisi Operasional}

Variabel yang diteliti terbatas pada kualitas layanan dan kepuasan konsumen. Variabel kualitas layanan memiliki indikator bukti langsung, kehandalan, daya tangkap, jaminan dan empati. Sedangkan kepuasan konsumen terkait dengan pelayanan, relasi, keluhan pelanggan, citra atau image positif.

\section{Teknik Pengumpulan Data}

Observasi yang dilakukan menggunakan bentuk observasi non partisipan, metode dimana peneliti tidak terlibat dalam kegiatan sehari-hari subjek yang sedang diamati atau yang digunakan sebagai sumber data penelitian karena peneliti hanya sebagai pengamat. Selain observasi peneliti juga menggunakan hasil pengisian kuesioner oleh pelanggan. Peneliti juga menggunakan dokumentasi untuk mencari data mengenai objek-objek yang diamati baik dalam bentuk foto-foto, maupun catatan-catatan penting berhubungan dengan penelitian.

\section{HASIL DAN PEMBAHASAN}

Hasil penelitian terkait kuesinoner setiap indikator akan diuraikan dan dibahas dalam bentuk tabel rekapan sebagai berikut;

Tabel 1. Rekapan Hasil Kuesioner Tangible (Bukti Fisik)

\begin{tabular}{|l|l|l|l|l|}
\hline \multicolumn{1}{|c|}{$\begin{array}{c}\text { Indikator } \\
\text { Tangible }\end{array}$} & $\begin{array}{c}\text { Kurang } \\
\text { Sekali }\end{array}$ & Kurang & Baik & $\begin{array}{c}\text { Baik } \\
\text { Sekali }\end{array}$ \\
\hline $\begin{array}{l}\text { Bagaimana } \\
\text { peralatan } \\
\text { dan } \\
\text { perlengkap } \\
\text { an yang } \\
\text { dipakai } \\
\text { oleh } \\
\text { petugas? }\end{array}$ & & & & \\
\hline $\begin{array}{l}\text { Penggunaa } \\
\mathrm{n} \text { tanda } \\
\text { pengenal } \\
\text { petugas } \\
\text { saat } \\
\text { melakukan } \\
\text { treatment }\end{array}$ & & & 30 & \\
\hline $\begin{array}{l}\text { Kerapian } \\
\text { dan } \\
\text { kebersihan } \\
\text { diri petugas }\end{array}$ & & & 30 & \\
\hline
\end{tabular}


Received: July, 142021

Revised: July, 232021

Available online : July, 242021

\begin{tabular}{|l|l|l|l|l|}
\hline $\begin{array}{l}\text { Kelengkap } \\
\text { an atribut } \\
\text { safety }\end{array}$ & & 1 & 29 & \\
\hline
\end{tabular}

Sumber : Hasil Olahan Peneliti, 2021.

Berdasarkan hasil kuesioner bukti fisik (tangible) diatas, hampir semua informan dari PT. Etos Suryanusa banyak yang memilih baik. Hal ini dilihat dari peralatan, perlengkapan yang digunakan kelengkapan atribut safety serta penampilan dari para petugas PT. Etos Suryanusa yang cukup memadai. Namun demikian, adanya satu informan yang memilih kurang yaitu dalam hal kelengkapan atribut safety dan menjadi perhatian penting agar petugas dapat memperbaiki kembali dengan kelengkapan atribut safety.

\section{Reliability (Kehandalan)}

Tabel 2. Rekapan Hasil Kuesioner Reliability (Kehandalan)

\begin{tabular}{|l|c|c|c|c|}
\hline $\begin{array}{l}\text { Indikator } \\
\text { Reliability }\end{array}$ & $\begin{array}{c}\text { Kurang } \\
\text { Sekali }\end{array}$ & Kurang & Baik & $\begin{array}{c}\text { Baik } \\
\text { Sekali }\end{array}$ \\
\hline $\begin{array}{l}\text { Registra } \\
\text { si sesuai } \\
\text { dengan } \\
\text { waktu } \\
\text { yang } \\
\text { telah } \\
\text { ditetapk } \\
\text { an }\end{array}$ & & & 30 & \\
\hline $\begin{array}{l}\text { Kecepat } \\
\text { an } \\
\text { pelayan } \\
\text { komplai } \\
n\end{array}$ & & & 28 & 2 \\
\hline
\end{tabular}

\begin{tabular}{|c|c|}
\hline $\begin{array}{l}\text { Kualitas } \\
\text { laporan } \\
\text { hasil } \\
\text { kerja }\end{array}$ & 30 \\
\hline
\end{tabular}

Sumber : Hasil Olahan Peneliti, 2021.

Dari hasil pengisian kuesioner reliability (kehandalan), kebanyakan informan PT. Etos Suryanusa lebih memilih poin baik. Hal ini dikarenakan kehandalan yang diberikan oleh PT. Etos Suryanusa berupa registrasi sesuai dengan waktu yang telah ditetapkan, kecepatan pelayanan komplain dan kualitas hasil dapat memuaskan pihak konsumen.

\section{Responsiveness (Daya Tangkap)}

Tabel 3. Rekapan Hasil Kuesioner Responsiveness (Daya Tangkap)

\begin{tabular}{|l|c|c|c|c|}
\hline $\begin{array}{c}\text { Indikator } \\
\text { Responsiveness }\end{array}$ & $\begin{array}{c}\text { Kurang } \\
\text { Sekali }\end{array}$ & Kurang & Baik & $\begin{array}{c}\text { Baik } \\
\text { Sekali }\end{array}$ \\
\hline $\begin{array}{l}\text { Petugas dengan } \\
\text { penuh kesiapan } \\
\text { untuk } \\
\text { memberikan } \\
\text { pelayanan }\end{array}$ & & 1 & 29 & \\
\hline $\begin{array}{l}\text { Adanya } \\
\text { kemauan } \\
\text { petugas dalam } \\
\text { memberikan } \\
\text { bantuan }\end{array}$ & & 30 & \\
\hline $\begin{array}{l}\text { Pelayanan yang } \\
\text { baik dan } \\
\text { mampu } \\
\text { menjelaskan } \\
\text { kepada } \\
\text { pelanggan }\end{array}$ & & & 30 & \\
\hline
\end{tabular}

Sumber : Hasil Olahan Peneliti, 2021. 
Received: July, 142021

Revised : July, 232021

Available online : July, 242021

Berdasarkan hasil rekapan kuesioner yang dibagi pada 30 informan, total keseluruhan informan terkait indikator assurance (jaminan) telah memilih poin baik. Hasil analisa yaitu berhasilnya PT. Etos Suryanusa dalam hal assurance (jaminan) khususnya yang bisa menanamkan kepercayaan pada pelanggan, keramahan di bidang administrasi dan komunikasi yang baik sehingga mampu memberikan hasil yang baik pada pelanggan.

\section{Empathy (Empati)}

Tabel 5. Rekapan Hasil Kuesioner Empathy (Empati)

\begin{tabular}{|l|c|c|c|c|}
\hline $\begin{array}{l}\text { Indikato } \\
\mathbf{r} \\
\text { Empathy }\end{array}$ & $\begin{array}{c}\text { Kura } \\
\text { ng } \\
\text { Sekal } \\
\text { i }\end{array}$ & $\begin{array}{c}\text { Kura } \\
\text { ng }\end{array}$ & $\begin{array}{c}\text { Bai } \\
\mathbf{k}\end{array}$ & $\begin{array}{c}\text { Baik } \\
\text { Sek } \\
\text { ali }\end{array}$ \\
\hline $\begin{array}{l}\text { Kebutuha } \\
\text { n } \\
\text { konsume } \\
\text { n sangat } \\
\text { dimenger } \\
\text { ti oleh } \\
\text { petugas }\end{array}$ & & 2 & 28 & \\
\hline $\begin{array}{l}\text { Penuh } \\
\text { perhatian } \\
\text { petugas } \\
\text { dalam } \\
\text { memberi } \\
\text { kan } \\
\text { perlakua } \\
\text { n } \\
\text { konsume } \\
\text { n }\end{array}$ & & 30 & \\
\hline $\begin{array}{l}\text { Komunik } \\
\text { asi yang } \\
\text { mudah }\end{array}$ & & & & \\
\hline
\end{tabular}

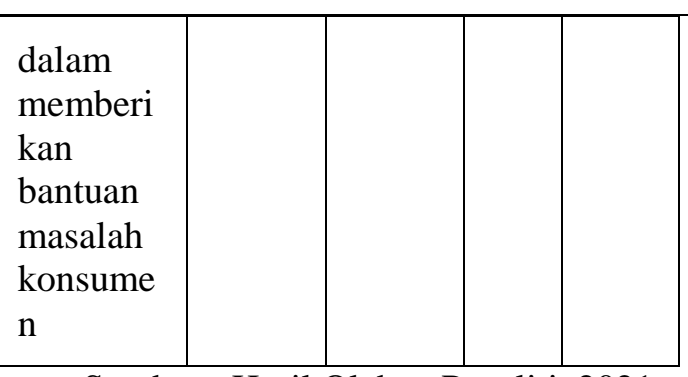

Sumber : Hasil Olahan Peneliti, 2021.

Dari hasil rekapan kuesioner terkait dengan empathy, banyaknya informan lebih memilih poin baik. Kemampuan dari petugas untuk memahami kebutuhan konsumen, memberikan perlakuan dengan baik dan penuh perhatian, komunikasi yang lancar dalam memberikan bantuan penanganan masalah konsumen. Meski demikian, terdapat dua informan yang merasa kurang dalam hal mengerti akan kebutuhan pelanggan dapat di jadikan evaluasi kembali.

Tabel 6. Rekapan Hasil Kuesioner Kepuasan Konsumen

\begin{tabular}{|l|c|}
\hline \multicolumn{1}{|c|}{ Indikator } & \multicolumn{1}{c|}{$\begin{array}{c}\text { Jumlah } \\
\text { informan }\end{array}$} \\
\hline Bukti langsung (Tangibles) & 4 \\
\hline Kehandalan (Reliability) & 21 \\
\hline $\begin{array}{l}\text { Daya tangkap } \\
\text { (Responsiveness) }\end{array}$ & 5 \\
\hline Jaminan (Assurance) & 0 \\
\hline Empati (Emphaty) & 0 \\
\hline Sumber : Hasil Olahan Peneliti, 2021.
\end{tabular}


Revised : July, 232021

Available online : July, 242021

Berdasarkan Tabel 6 dapat disimpulkan bahwa faktor reliability (kehandalan) merupakan pilihan penting pertama informan dalam meningkatkan kepuasan konsumen. Selanjutnya pilihan penting kedua informan adalah faktor responsiveness (daya tangkap) yang dapat meningkatkan kepuasan konsumen. Pilihan penting ketiga adalah faktor tangible (bukti langsung) dalam meningkat kepuasan konsumen. Untuk faktor assurance (jaminan) dan emphaty (empati) tidak dipilih oleh informan sebagai faktor penting yang meningkatkan kepuasan konsumen dengan lain kata menunjukan bahwa faktor jaminan dan empati tidak ada pengaruh dalam kepuasan konsumen.

\section{KESIMPULAN}

\section{Simpulan}

Adapun rangkuman yang diperoleh dalam penelitian ini adalah sebagai berikut

1. Proses pelayanan di PT. Etos Suryanusa dari sudut pandang informan sudah maksimal dan memuaskan. Didukung dengan peralatan yang digunakan perusahaan sudah memadai, penampilan yang baik para petugas, kecekatan dan ketepatan waktu perusahaan dalam melayani pelanggan, kesiapan perusahaan yang baik dalam melakukan treatment, perusahaan memberikan suatu pelayanan yang sudah dipandang baik oleh konsumen dan setiap penjelasan komunikasi perusahaan dengan mudah dipahami oleh konsumen. Namun, terdapat faktor yang dianggap masih kurang mampunya perusahaan dalam memberikan kepercayaan kepada konsumen, kurangnya keramahan bagian administrasi dalam melayani pelanggan, petugas yang susah dihubungi oleh pelanggan.

2. Faktor bukti langsung, kehandalan dan daya tangkap dipilih konsumen sebagai faktor yang dapat mempengaruhi kepuasan konsumen. Dari ketiga faktor tersebut, faktor kehandalan memiliki pengaruh yang sangat besar dan signifikan terhadap kepuasan konsumen PT Etos Suryanusa.

3. Konsumen tidak memilih faktor jaminan dan empati sebagai faktor yang menentukan kepuasan konsumen. Sama artinya faktor 
jaminan dan empati tidak memiliki pengaruh terhadap kepuasan konsumen.

\section{Implikasi Penelitian}

Berikut implikasi yang terkait dengan penelitian ini sebagai berikut:

1. Bukti langsung, sebagai salah satu indikator yang mampu mempengaruhi kepuasan konsumen pada PT. Etos Suryanusa. Dibuktikan dengan rekapan hasil kuesioner informan. Maka dari itu PT. Etos Suryanusa harus melakukan peremajaan pada peralatan peralatan yang di pakai agar dapat mempermudah pekerjaan petugas di area konsumen.

2. Kehandalan, merupakan indikator yang sangat dominan mempengaruhi kepuasan konsumen dengan dibuktikan rekapan data kuesioner. Dari kondisi tersebut PT. Etos Suryanusa akan menambah kembali tim khusus untuk cepat menanggapi keluhan para pelanggan agar kepuasan konsumen lebih meningkat lagi.

3. Daya tangkap, indikator daya tangkap ini merupakan hal penting untuk mengerti akan kebutuhan pelanggan. Maka dari itu, petugas PT. Etos Suryanusa harus membuat program baru berupa kunjungan tambahan pada konsumen yang masih kurang puas untuk lebih memaksimalkan dalam hal pengendalian hama.

4. Jaminan, indikator jaminan dalam perusahaan jasa seperti PT. Etos Suryanusa yang harus menjadi perhatian adalah masalah komunikasi. Menjaga komunikasi yang baik agar pelanggan lebih percaya dan lebih nyaman kerjasama dengan PT. Etos Suryanusa. Maka dari itu, petugas PT. Etos Suryanusa dapat diberi training terkati komunikasi agar dapat dipahami lebih baik lagi.

5. Empati, keinginan dan kebutuhan konsumen harus menjadi perhatian perusahaan. Secara rutin dan periodik, perusahaan melakukan kunjungan konsumen dan cekat dalam merespon pelanggan.

\section{Saran}

Penyebaran sampel penelitian yang tidak merata dalam golongan konsumen. Penelitian ini lebih banyak mengambil sampel golongan konsumen perumahan sedangkan konsumen perusahaan bukan saja golongan perumahan tetapi terdapat juga golongan konsumen perkantoran dan industri. Penelitian selanjutnya lebih dapat 
Revised : July, 232021

Available online : July, 242021

meneliti dengan jangkuan golongan

konsumen yang lebih merata

\section{DAFTAR PUSTAKA}

Candrianto, S. M. 2021. Kepuasan Pelanggan Suatu Pengantar. Malang, Jawa Timur: Literasi Nusantara.

Hakim, L. N. (2021). Effect of Product Quality and Service Quality on Customer Loyalty with Customer Satisfaction as an Intervenning Variables (Case Study on the Tirta Jasa Lampung Selatan Regional Company (PDAM)). Economit Journal: Scientific Journal of Accountancy, Management and Finance, 1(1), 48-56. https://doi.org/10.33258/economit.v1i 1.374

Hamdi, A. S. 2014. Metode Penelitian Kuantitatif Aplikasi dalam Pendidikan. Yogyakarta: CV Budi Utama.

Kamaludin, Ahmad. 2019. Hubungan Kualitas Pelayanan Terhadap Kepuasan Konsumen Pada Apotik Puji Lestari Majalengka. Syntax Literate, 4 (12), 47-55.

Kotler, P. 2002. Manajemen Pemasaran di Indonesia. Jakarta: Salemba Empat.

Kotler, P. 2002. Manajemen Perusahaan Terjemahan Hendra Teguh, Edisi Milenium, Cetakan Pertama. Jakarta: Prenhalindo.

Krisdianti, DL. 2019. Pengaruh Kualitas Pelayanan Terhadap Kepuasan Konsumen Pada Restoran Pizza Hut Malang Town Square. Jurnal Administrasi Bisnis (JAB), 70 (1), 36-44.

Setiawan, Ajis. 2019. Pengaruh Kualitas Pelayanan Terhadap Kepuasan Konsumen. JSMBI (Jurnal Sains
Manajemen Dan Bisnis Indonesia ), 9 (2), 114-126.

Tjiptono, F. 2007. Strategi Pemasaran. Yogyakarta: Andi Ofset.

Wedastra, M. S. 2020. Pengendalian Hama Penyakit Terpadu untuk Mengurangi Kerusakan. Jurnal Gema Ngabdi, 02, 90.

Wijaya, T. 2018. Manajemen Kualitas Jasa. Jakarta: PT. Indeks. 